\title{
The Impact of Socioeconomic Status on Staging, Prognosis in Hepatocellular Carcinoma
}

\author{
Yongjie Zhou ${ }^{1-3, *}$, Wen Zhang ${ }^{1-3, *}$, Jingqin Ma ${ }^{1-3}$, Zihan Zhang ${ }^{1-3}$, Minjie Yang ${ }^{1-3}$, Jianjun Luo ${ }^{1-4}$, \\ Zhiping Yan ${ }^{1-4}$
}

'Department of Interventional Radiology, Zhongshan Hospital, Fudan University, Shanghai, People's Republic of China; ${ }^{2}$ Shanghai Institution of Medical Imaging, Shanghai, People's Republic of China; ${ }^{3}$ National Clinical Research Center for Interventional Medicine, Zhongshan Hospital, Fudan University, Shanghai, People's Republic of China; ${ }^{4}$ Center for Tumor Diagnosis and Therapy, Jinshan Hospital, Fudan University, Shanghai, People's Republic of China

*These authors contributed equally to this work

Correspondence: Jianjun Luo; Zhiping Yan, Department of Interventional Radiology, Zhongshan Hospital, Fudan UniversityNo. I80 Fenglin Road, Shanghai, 200032, People's Republic of China, Email luo.jianjun@zs-hospital.sh.cn; yan.zhiping@zs-Hospital.sh.cn

\begin{abstract}
Purpose: We conducted this large population-based study to evaluate the impact of socioeconomic status (SES) factors on cancerspecific survival (CSS) of patients with hepatocellular carcinoma (HCC). We further assessed the value of a novel TNM-SES staging system, which incorporated these SES factors with TNM stage on staging and prognosis.

Methods: A total of 13,791 patients diagnosed with HCC from 2012 to 2016 were retrieved from one large population database. Cox proportional hazards regression model and Harrell's concordance index (C-index) were used to identify the SES factors associated with CSS and analyze the prognostic value of TNM-SES stage. Kaplan-Meier curves and Log rank test were performed to evaluate CSS.

Results: Four SES factors (marital status, insurance status, education, household income) were identified as the prognostic factors associated with CSS. The SES-2 (lower SES) stage was significantly correlated to unfavorable CSS of the patients with HCC, with a $32.0 \%$ increased risk $(\mathrm{HR}=1.32,95 \% \mathrm{CI}(1.26-1.39), \mathrm{P}<0.001)$, after adjusting for several confounders. The C-index of the TNMSES stage was 0.735 (95\% CI (0.729-0.741)) which was higher than that of the TNM stage $(0.718,95 \%$ CI $(0.712-0.724))$, indicating a high accuracy of prognostic prediction.

Conclusion: Our comprehensive study revealed that SES was significantly associated with prognosis of patients with HCC after adjusting several confounders. The novel TNM-SES staging system which combined TNM stage and SES stage had more superior predictive value than the traditional TNM stage. Disparity on SES should receive more attention for patients with HCC in clinical management.
\end{abstract}

Keywords: socioeconomic status, TNM stage, hepatocellular carcinoma SEER database

\section{Introduction}

Hepatocellular carcinoma (HCC) is the most common cancer and the third leading cause of cancer-related deaths worldwide. ${ }^{1}$ Despite great advances had been made in the treatment modality for HCC, the prognosis of HCC remains dismal with 1 -year survival $<50 \%,{ }^{2}$ due only to several therapies, such as hepatic surgery, ablation and transplantation, were curative methods for early-stage disease. ${ }^{3}$ The survival outcome of patients with HCC is influenced by various variates, including biological factors and socioeconomic status (SES). The impact of biological factors on the prognosis of patients with HCC has been extensively investigated, such as sex, AFP level, portal vein invasion and so on. ${ }^{4-8}$ Recently, the effect of SES on cancer survival has received considerable interests. SES contains household income, educational attainment, employment status, insurance status and marital status, and encompasses quality of life attributes as well as the opportunities and privileges afforded to people within society. Previous studies ${ }^{9,10}$ have indicated that patients with HCC with low SES status have an advanced stage at diagnosis and a worse prognosis. However, as far as 
we know, the effect of SES on the tumor stage at diagnosis and the prognosis of patients with HCC has not yet been investigated together as an independent parameter.

The American Joint Committee on Cancer (AJCC) staging system has been widely used to stratify patients for treatment strategy and predictive prognosis in clinical management. Nevertheless, the TNM staging system only incorporates the size and extent of the tumor ( $\mathrm{T}$ stage), the number of nearby positive lymph nodes ( $\mathrm{N}$ stage) and whether to metastasis (M stage), without involvement of the SES of patients, which also plays a critical role in prognosis of patients with HCC. Hence, a novel staging system for patients with HCC, which combines traditional TNM stage and SES stage, is needed to accurately predict prognosis in clinical management. In this large population-based study, we firstly evaluated the effect of several SES factors, including insurance status, marital status, country percentage with bachelor's degree, country-level median household income and country percentage with employment on cancer-specific survival (CSS) of patients with HCC using the data from the Surveillance, Epidemiology, and End Results (SEER) database. Accordingly, the SES stage was generated by severe SES factors associated with CSS. Ultimately, we constructed a novel TNM-SES stage system, which incorporated the traditional TNM stage with SES stage, and further evaluated its prognostic value in clinical management.

\section{Materials and Methods}

\section{Database and Patient Selection}

We obtained the clinical information of patients with HCC from the Surveillance, Epidemiology, and End Results (SEER) program (1973-2016), which collects and publishes cancer incidence and survival data from population-based registries covering about $28 \%$ of the population of the United States. Patients who were diagnosed with primary HCC between January 12012 and December 312016 were retrieved for our study, with the primary site code (C22.0) and histological types codes (8170/3-8175/3). The SES information of the patients with HCC was analyzed in our study, including insurance status, marital status, country percentage with bachelor's degree, country-level median household income and country percentage with employed. The classifications of insurance status and marital status were based on the data from the SEER program. The classifications of country percentage with bachelor's degree and country percentage with employed were according to the quadratic method of the number of patients in our study, while we divided the group of country-level median household income in line with the classification of household income in the United States. We only enriched the patients with aged 18-65 years at diagnosis because patients aged $\geq 65$ years were qualified for Medicare in USA, which may cause research bias in our study. The patients without survival time $>1$ month and adequate clinical information were excluded in our study.

\section{The Classification of SES Stage}

Four SES factors associated with cancer-specific survival (CSS) were selected using Cox proportional hazards regression model, including insurance status, marital status, country percentage with bachelor's degree and country-level median household income. As shown in Figure 1, patients in our study were sorted out by the different status of four important SES factors. The corresponding hazard ratios (HRs) values which were obtained by Cox proportional hazards regression model were assigned as the parameter values to indicate the status of patients with each of the four SES factors. The SES prognostic scores of patients were calculated by adding the parameter values of four significant SES factors. The SES prognostic scores ranged from 3.64 to 4.44 in our study, with a score of 3.64 indicating the optimal survival outcome and a score of 4.44 indicating the dismal survival outcome. Then, patients were divided into two groups on the basis of cutoff SES prognostic score (score of 3.93), which was the median SES prognostic scores. Patients with SES prognostic scores $<3.93$ were allocated into SES-1 stage group (higher SES), while patients in SES-2 stage group (lower SES) were with SES prognostic scores $>3.93$. For example, the SES prognostic score of a patient who was Medicaid (1.19) and Divorced (1.11) and lived in the country where $31.24 \%-39.07 \%$ people with bachelor's degree (0.89) and the country with 45.00 $59.99 \mathrm{~K}$ of median household income (0.97), was 4.16, and then this patient was allocated into SES-2 stage group. Finally, a new staging system (TNM-SES stage) was achieved by combining TNM stage (I, II, IIIA, IIIB, IIIC, IVA, IVB) with SES-1 stage or SES-2 stage. 


\begin{tabular}{|c|c|c|c|}
\hline $\begin{array}{c}\text { Insurance } \\
\text { status (points) }\end{array}$ & $\begin{array}{c}\text { Marital } \\
\text { status(points) }\end{array}$ & $\begin{array}{l}\text { Country \% with } \\
\text { bachelor degree } \\
\text { (points) }\end{array}$ & $\begin{array}{c}\text { Country-level } \\
\text { median household } \\
\text { income (points) }\end{array}$ \\
\hline $\begin{array}{l}\text { Insured } \\
(1.00)\end{array}$ & $\begin{array}{c}\text { Married } \\
(1.00)\end{array}$ & $\begin{array}{c}7.64-22.82 \% \\
(1.00)\end{array}$ & $\begin{array}{c}19.26-44.99 \mathrm{~K} \\
(1.00)\end{array}$ \\
\hline \multirow{2}{*}{$\begin{array}{l}\text { Medicaid } \\
(1.19)\end{array}$} & $\begin{array}{c}\text { Never married } \\
(1.08)\end{array}$ & $\begin{array}{c}22.83-31.23 \% \\
(0.95)\end{array}$ & $\begin{array}{c}45.00-59.99 \mathrm{~K} \\
(0.97)\end{array}$ \\
\hline & $\begin{array}{c}\text { Divorced } \\
(1.11)\end{array}$ & $\begin{array}{c}31.24 \%-39.07 \% \\
(0.89)\end{array}$ & $\begin{array}{c}60.00-74.99 \mathrm{~K} \\
(0.83)\end{array}$ \\
\hline $\begin{array}{l}\text { Uninsured } \\
(1.33)\end{array}$ & $\begin{array}{c}\text { Widowed } \\
(1.11)\end{array}$ & $\begin{array}{c}39.08-57.51 \% \\
(0.86)\end{array}$ & $\begin{array}{c}74.99-110.97 \mathrm{~K} \\
(0.78)\end{array}$ \\
\hline
\end{tabular}

Figure I The socioeconomic status (SES) prognostic scores of the patients with HCC.

\section{Statistical Analysis}

Categorical variables were presented as frequencies and evaluated using the chi-square test or Fisher's exact test. The endpoint was cancer-specific survival (CSS), defined as the time from the time of diagnosis until death from HCC. Univariate and multivariate survival analyses were performed using Cox proportional hazards regression model. The hazard ratios (HRs) with their $95 \%$ confidence intervals (95\% CIs) were calculated. The survival analysis of different factors was evaluated by using the Kaplan-Meier curves and Log rank test. We further assessed the performance of two staging systems (TNM stage and TNM-SES stage) using Harrell's concordance index (C-index), where a larger value indicates better prognosis. The statistical analysis was performed using R software (version 3.5.1) and GraphPad Prism software version 6.0 (GraphPad Software, Inc., La Jolla, CA). All tests were two-sided, and p $<0.05$ was considered statistically significant.

\section{Results}

\section{Overall Characteristics of the HCC Patients}

Using the SEER program, a total of 13,791 patients diagnosed with primary HCC between January 12012 and December 312016 were identified in our study. The clinical characteristics of the included patients is showed in Table 1. Overall, a majority of patients with HCC were male $(82.7 \%)$, white $(68.1 \%)$ and with age of 56-60 years (37.0\%). More than half of the patients (54.8\%) had localized-stage HCC at initial diagnosis and $16.5 \%$ patients had distant-stage HCC. The most common TNM stage in our study was stage I with 5482 patients (39.8\%). In terms of SES factors, most patients were insured (62.3\%) and married (48.4\%). Notably, only $8.6 \%$ patients and $6.5 \%$ patients had received hepatic surgery and liver transplant, respectively. Approximately half of patients (54.2\%) had undertaken chemotherapy.

\section{Four SES Factors Related to CSS of Patients with HCC}

During follow-up, 55.9\% ( $\mathrm{N}=7713)$ of patients with HCC died. As shown in Table 2, univariate analysis indicated that age, sex, race, stage, TNM stage, insurance status, marital status, country percentage with bachelor's degree, country percentage with employed, country-level median household income, surgery and chemotherapy were significantly associated with CSS. Then, we added these factors into the multivariate analysis. The results showed that these four SES factors (insurance status, marital status, country percentage with bachelor's degree and country-level median household income) were related to CSS. Other important predictors also included age, sex, race, stage, TNM stage, surgery and chemotherapy.

\section{Baseline Characteristics of Patients with HCC in Two SES-Stage}

Based on the cutoff SES prognostic score, 6860 included patients $(49.7 \%)$ were allocated to SES-1 (higher SES) stage group, and 6931 (50.3\%) patients were assigned to SES-2 (lower SES) stage group. As illustrated in Table S1, there were significant differences in most parameters (except sex) between the two SES stages. Patients aged 61-65 years in SES-1 
Table I The Characteristics of Patients with Hepatocellular Carcinoma

\begin{tabular}{|c|c|c|}
\hline Characteristic & & No. (\%) \\
\hline \multirow[t]{4}{*}{ Age } & $\leq 50$ & $1719(12.5)$ \\
\hline & $51-55$ & $2865(20.8)$ \\
\hline & $56-60$ & $5100(37.0)$ \\
\hline & $\geq 65$ & $4107(29.8)$ \\
\hline \multirow[t]{2}{*}{ Sex } & Female & $2391(17.3)$ \\
\hline & Male & II,400 (82.7) \\
\hline \multirow[t]{3}{*}{ Race } & White & $9397(68.1)$ \\
\hline & Black & $2282(16.5)$ \\
\hline & Other* & $2112(15.3)$ \\
\hline \multirow[t]{3}{*}{ Stage } & Localized & $7563(54.8)$ \\
\hline & Regional & 3954 (28.7) \\
\hline & Distant & $2274(16.5)$ \\
\hline \multirow[t]{7}{*}{ TNM stage } & 1 & $5482(39.8)$ \\
\hline & II & $2995(21.7)$ \\
\hline & IIIA & $1209(8.8)$ \\
\hline & IIIB & $1057(7.7)$ \\
\hline & IIIC & $233(1.7)$ \\
\hline & IVA & $616(4.5)$ \\
\hline & IVB & $2199(15.9)$ \\
\hline \multirow[t]{3}{*}{ Insurance } & Insured & $8587(62.3)$ \\
\hline & Medicaid & $4353(31.6)$ \\
\hline & Uninsured & $851(6.2)$ \\
\hline \multirow[t]{4}{*}{ Marital status } & Married & $6668(48.4)$ \\
\hline & Never married & $4220(30.6)$ \\
\hline & Divorced & $2433(17.6)$ \\
\hline & Widowed & $470(3.4)$ \\
\hline \multirow[t]{4}{*}{ Country $\%$ with bachelor degree } & $7.64-22.82 \%$ & $3663(26.6)$ \\
\hline & $22.83-31.23 \%$ & $3419(24.8)$ \\
\hline & $31.24 \%-39.07 \%$ & $3662(26.6)$ \\
\hline & $39.08-57.51 \%$ & $3047(22.1)$ \\
\hline \multirow[t]{4}{*}{ Country-level median household income ${ }^{* *}$} & $19.26-44.99 \mathrm{~K}$ & $1867(13.5)$ \\
\hline & $45.00-59.99 \mathrm{~K}$ & $3361(24.4)$ \\
\hline & $60.00-74.99 \mathrm{~K}$ & $5180(37.6)$ \\
\hline & $74.99-110.97 \mathrm{~K}$ & $3383(24.5)$ \\
\hline \multirow[t]{4}{*}{ Country $\%$ with employed } & $1.29-5.8 \%$ & $3682(26.7)$ \\
\hline & $5.81-7.06 \%$ & $3595(26.1)$ \\
\hline & $7.07-8.53 \%$ & $3166(23.0)$ \\
\hline & $8.54-17.16 \%$ & $3348(24.3)$ \\
\hline \multirow[t]{3}{*}{ Surgery } & No surgery & $11,712(84.9)$ \\
\hline & Surgery & II $88(8.6)$ \\
\hline & Transplant & $891(6.5)$ \\
\hline \multirow[t]{2}{*}{ Chemotherapy } & No & $7475(54.2)$ \\
\hline & Yes & $6316(45.8)$ \\
\hline
\end{tabular}

Notes: Indicates American Indian/AK Native, Asian/Pacific Islander, and unknown. **Shown in US dollars.

stage had higher rate than those in SES-2 stage $(32.7 \%$ vs $26.9 \%, \mathrm{P}<0.001)$. Patients in SES-2 stage were more likely to be Black than those with higher SES $(20.4 \%$ vs $12.6 \%$, P $<0.001)$. High rates of Localized-stage HCC and TNM I-II stage HCC were seen in patients in SES-1 stage than those with in SES-2 stage (57.8\% vs $51.9 \%, 41.7 \%$ vs $37.9 \%$, $23.3 \%$ vs $20.2 \%$, overall $\mathrm{P}<0.001)$. As expected, patients in SES-1 stage had lower rates of unemployment $(\mathrm{P}<0.001)$. Patients in SES-1 stage were more likely to receive hepatic resection or liver transplant than those patients in SES-2 stage 
Table 2 Univariate and Multivariate Analysis of CSS of Patients with HCC

\begin{tabular}{|c|c|c|c|c|}
\hline \multirow[t]{2}{*}{ Variables } & \multicolumn{2}{|c|}{ Univariate Analysis } & \multicolumn{2}{|c|}{ Multivariate Analysis } \\
\hline & HR (95\%Cl) & p value & HR (95\%Cl) & p value \\
\hline \multicolumn{5}{|l|}{ Age } \\
\hline$\leq 50$ & I(Reference) & I & I(Reference) & I \\
\hline $51-55$ & $1.09(1.01-1.18)$ & $0.031^{*}$ & $1.11(1.03-1.20)$ & $0.010^{*}$ \\
\hline $56-60$ & $1.04(0.97-1.12)$ & 0.300 & $1.04(0.96-1.12)$ & 0.320 \\
\hline$\geq 65$ & $0.99(0.92-1.07)$ & 0.828 & $1.03(0.95-1.11)$ & 0.515 \\
\hline \multicolumn{5}{|l|}{ Sex } \\
\hline Female & I(Reference) & 1 & I (Reference) & I \\
\hline Male & $1.38(1.29-1.47)$ & $<0.001^{*}$ & $1.20(1.13-1.28)$ & $<0.001^{*}$ \\
\hline \multicolumn{5}{|l|}{ Race } \\
\hline White & I(Reference) & 1 & I(Reference) & I \\
\hline Black & $1.25(1.18-1.33)$ & $<0.001^{*}$ & $1.07(1.01-1.04)$ & $0.032^{*}$ \\
\hline Other** & $0.88(0.82-0.94)$ & $<0.001^{*}$ & $0.98(0.92-1.05)$ & 0.612 \\
\hline \multicolumn{5}{|l|}{ Stage } \\
\hline Localized & I(Reference) & 1 & I (Reference) & 1 \\
\hline Regional & $2.8 I(2.67-2.96)$ & $<0.001^{*}$ & $1.40(1.29-1.51)$ & $<0.001^{*}$ \\
\hline Distant & $6.88(6.48-7.31)$ & $<0.001^{*}$ & $1.44(1.08-1.93)$ & $0.014^{*}$ \\
\hline \multicolumn{5}{|l|}{ TNM stage } \\
\hline I & I(Reference) & 1 & I(Reference) & I \\
\hline ॥ & $1.23(1.15-1.32)$ & $<0.001^{*}$ & $1.20(1.12-1.30)$ & $<0.001^{*}$ \\
\hline IIIA & $3.5 \mathrm{I}(3.25-3.80)$ & $<0.001^{*}$ & $2.92(2.66-3.20)$ & $<0.001^{*}$ \\
\hline IIIB & $5.12(4.72-5.55)$ & $<0.001^{*}$ & $3.53(3.16-3.94)$ & $<0.001^{*}$ \\
\hline IIIC & $5.04(4.34-5.85)$ & $<0.001^{*}$ & $3.99(3.33-4.48)$ & $<0.001^{*}$ \\
\hline IVA & $4.63(4.20-5.11)$ & $<0.001^{*}$ & $3.14(2.78-3.56)$ & $<0.001^{*}$ \\
\hline IVB & $7.86(7.37-8.40)$ & $<0.001^{*}$ & $4.77(3.54-6.43)$ & $<0.001^{*}$ \\
\hline \multicolumn{5}{|l|}{ Insurance status } \\
\hline Insured & I(Reference) & I & I(Reference) & I \\
\hline Medicaid & I.42(1.36-1.49) & $<0.001^{*}$ & $1.19(1.13-1.25)$ & $<0.001^{*}$ \\
\hline Uninsured & $2.12(1.95-2.30)$ & $<0.001^{*}$ & $1.33(1.22-1.45)$ & $<0.001^{*}$ \\
\hline \multicolumn{5}{|l|}{ Marital status } \\
\hline Married & I (Reference) & 1 & I (Reference) & I \\
\hline Never married & $1.36(1.30-1.44)$ & $<0.001^{*}$ & $1.08(1.02-1.14)$ & $0.006^{*}$ \\
\hline Divorced & $1.31(1.23-1.39)$ & $<0.001^{*}$ & $1.11(1.08-1.19)$ & $0.001^{*}$ \\
\hline Widowed & $1.15(1.01-1.30)$ & $0.037^{*}$ & I.II(0.97-2.26) & 0.119 \\
\hline \multicolumn{5}{|c|}{ Country $\%$ with bachelor degree } \\
\hline $7.64-22.82 \%$ & I(Reference) & 1 & I(Reference) & I \\
\hline $22.83-31.23 \%$ & $0.89(0.83-0.94)$ & $<0.001^{*}$ & $0.95(0.88-1.03)$ & 0.204 \\
\hline $31.24 \%-39.07 \%$ & $0.83(0.78-0.88)$ & $<0.001^{*}$ & $0.89(0.83-0.98)$ & $0.014^{*}$ \\
\hline $39.08-57.51 \%$ & $0.7 I(0.67-0.76)$ & $<0.001^{*}$ & $0.86(0.78-0.95)$ & $0.004^{*}$ \\
\hline \multirow{2}{*}{\multicolumn{5}{|c|}{$\begin{array}{l}\text { Country-level median household } \\
\text { income*** }\end{array}$}} \\
\hline & & & & \\
\hline $19.26-44.99 \mathrm{~K}$ & I(Reference) & 1 & I(Reference) & I \\
\hline $45.00-59.99 \mathrm{~K}$ & $0.91(0.84-0.97)$ & $0.006^{*}$ & $0.97(0.90-1.05)$ & 0.421 \\
\hline $60.00-74.99 \mathrm{~K}$ & $0.76(0.7 \mid-0.8 I)$ & $<0.001^{*}$ & $0.83(0.76-0.91)$ & $<0.001^{*}$ \\
\hline 74.99-II0.97K & $0.65(0.6 \mathrm{I}-0.70)$ & $<0.001^{*}$ & $0.78(0.69-0.87)$ & $<0.001^{*}$ \\
\hline \multicolumn{5}{|c|}{ Country $\%$ with employed } \\
\hline $1.29-5.8 \%$ & I (Reference) & 1 & I(Reference) & I \\
\hline $5.8 I-7.06 \%$ & $1.14(1.07-1.21)$ & $<0.001^{*}$ & $0.99(0.93-1.07)$ & 0.972 \\
\hline $7.07-8.53 \%$ & $1.15(1.06-1.24)$ & $<0.001^{*}$ & $0.93(0.86-1.01)$ & 0.126 \\
\hline $8.54-17.16 \%$ & $1.24(1.17-1.33)$ & $<0.001^{*}$ & $0.89(0.85-1.03)$ & $0.071^{*}$ \\
\hline
\end{tabular}

(Continued) 
Table 2 (Continued).

\begin{tabular}{|c|c|c|c|c|}
\hline \multirow[t]{2}{*}{ Variables } & \multicolumn{2}{|c|}{ Univariate Analysis } & \multicolumn{2}{|c|}{ Multivariate Analysis } \\
\hline & HR (95\%Cl) & p value & HR (95\%Cl) & p value \\
\hline \multicolumn{5}{|l|}{ Surgery } \\
\hline no surgery & I (Reference) & I & I (Reference) & 1 \\
\hline surgery & $0.30(0.27-0.33)$ & $<0.001^{*}$ & $0.32(0.29-0.36)$ & $<0.001^{*}$ \\
\hline transplant & $0.07(0.06-0.09)$ & $<0.001^{*}$ & $0.10(0.08-0.12)$ & $<0.001^{*}$ \\
\hline \multicolumn{5}{|l|}{ Chemotherapy } \\
\hline No & I (Reference) & I & I (Reference) & I \\
\hline Yes & $0.75(0.7 \mathrm{I}-0.78)$ & $<0.001^{*}$ & $0.10(0.55-0.61)$ & $<0.001^{*}$ \\
\hline
\end{tabular}

Notes: *Indicates significance of $\mathrm{P}<0.05$. **Indicates American Indian/AK Native, Asian/Pacific Islander and unknown. ***Shown in US dollars. Abbreviations: CSS, cancer-specific survival; $\mathrm{HCC}$, hepatocellular carcinoma; $\mathrm{HR}$, hazard ratio; $\mathrm{Cl}$, confidence interval.

$(10.9 \%$ vs $6.3 \%, 7.7 \%$ vs $5.2 \%, \mathrm{P}<0.001)$. The higher rate of chemotherapy was also observed in patients in SES-1 stage $(48.0 \%$ vs $43.6 \%, \mathrm{P}<0.001)$.

\section{SES Stage Associated with CSS of Patients with HCC}

Multivariate Cox regression analysis indicated that SES-2 stage was significantly correlated to CSS of the patients with HCC, with a $32.0 \%$ increased risk ( $\mathrm{HR}=1.32,95 \%$ CI $(1.26-1.39), \mathrm{P}<0.001)$, as shown in Table S2. The Kaplan-Meier curves also showed that the patients in SES-1 stage had better prognosis than those in SES-2 stage $(\mathrm{P}<0.001)$, as shown in Figure 2. We further analyzed the effect of SES stage on CSS of patients in each stage (localized, regional and distant), the survival curves also indicated the better outcome of CSS in patients with higher SES, compared with those with lower SES $(\mathrm{P}<0.001, \mathrm{P}<0.001, \mathrm{P}=0.0062$, respectively). Furthermore, the stratified analysis of CSS by age, sex and race showed the consistent results (all $\mathrm{P}<0.001$ ), as presented in Figure S1.

\section{Prognostic Value of TNM-SES Stage}

The concordance index (C-index) of the TNM-SES stage was 0.735, (95\% CI (0.729-0.741)) which was higher than that of the TNM stage $(0.718,95 \% \mathrm{CI}(0.712-0.724))$, indicating a high accuracy of prediction. AS presented in Figure 3 , the vast majority of patients with SES-1 stage (expect IIIC) showed better prognosis than those with SES-2 stage in the same TNM stage. Interestingly, some patients with SES-1 stage had an increased CSS, compared with patients with SES-2 stage and a lower TNM stage, such as II-S1 vs I-S2. $(\mathrm{p}<0.001)$.

The HRs of each TNM-SES stage were demonstrated by using the Cox proportional hazards regression model, as shown in Figure 4. In line with the Kaplan-Meier curves, patients with SES-1 stage had lower HR than those with SES-2 stage at same TNM stage. It is worth mentioning that a higher HR was observed in patients with SES-2 stage compared with patients with SES-1 stage and more TNM stage. For instance, patients with II-S1 stage (HR $=1.26,95 \%$ CI $(1.13-$ 1.39)) had an increase CSS than patients with I-S2 stage (HR $=1.65,95 \%$ CI (1.51-1.80)). Notably, except for the IVB stage, the patients with IIIB-S2 had the highest HR (7.72, 95\% CI (6.89-8.66)) than patients who had IIIC or IVA stage. The HRs of IIIB, IIIC and IVA stages were almost the same.

\section{Discussion}

The impact of socioeconomic status (SES) on the prognosis and clinical management of cancer patients had received more attention. Several investigations ${ }^{10-12}$ indicated that SES disparities, such as marital status, insurance status and household income were associated with the cancer stage of diagnosis and survival outcome of patients with HCC. However, as far as we know, few studies had investigated more than three SES factors in one research and not involved TNM staging system as an independent parameter. In this large-scale study, four SES factors (insurance status, marital status, country percentage with bachelor's degree and country-level median household income) associated with CSS of patients with HCC were identified to construct a SES stage, which divided the eligible patients into SES-1 stage (higher 

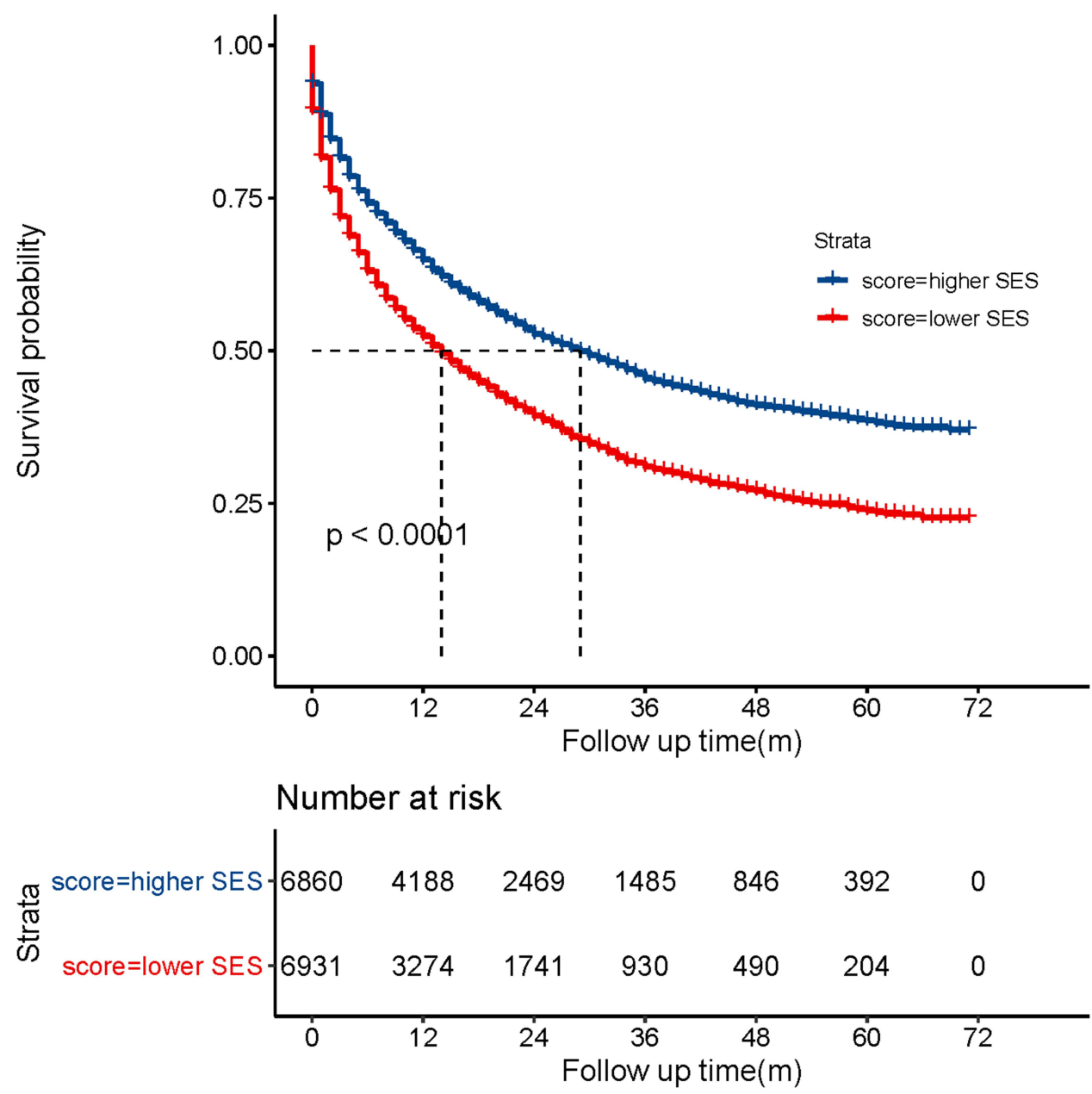

Figure 2 Kaplan-Meier curve shows the cancer-specific survival (CSS) of patient with HCC in two SES stage.
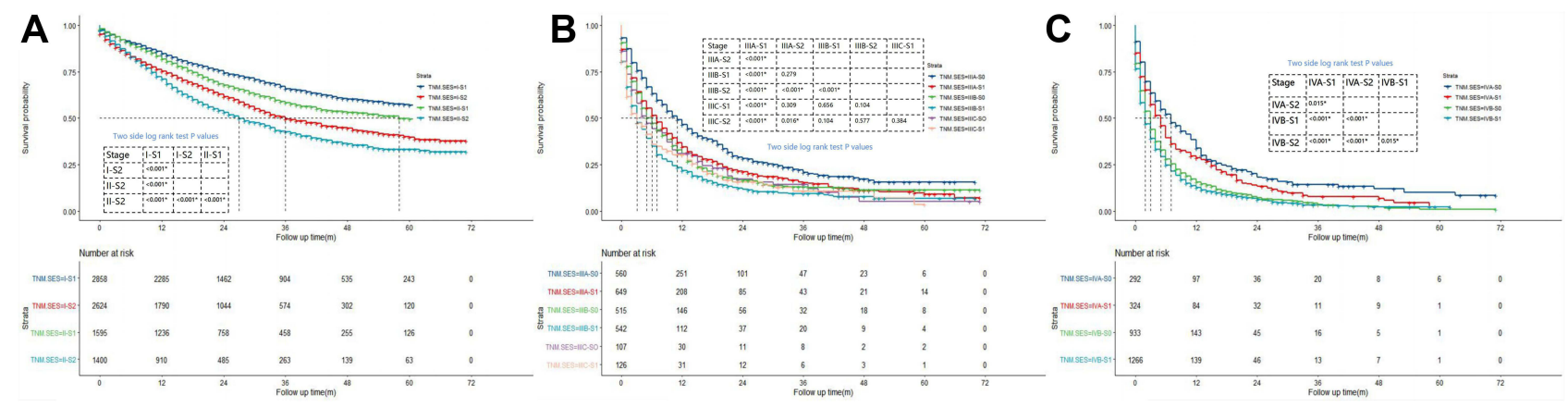
for TNM I-II, (B) for IIIA-IIIC, (C) for IVA-IVB.

socioeconomic status) and SES-2 stage (lower socioeconomic status). Subsequently, a superior staging system was generated for predictive prognosis by combining the TNM stage and the SES stage.

The previous study ${ }^{13}$ based on a large population of more than one million cancer patients in the United States indicated that unmarried patients had a higher-risk of presentation with metastasis, under-utilization of definitive treatment and unfavorable survival outcome, compared with married patients. Several investigations ${ }^{14-16}$ also demonstrated that marital status was significantly associated with prognosis in HCC and other cancers. In line with these 


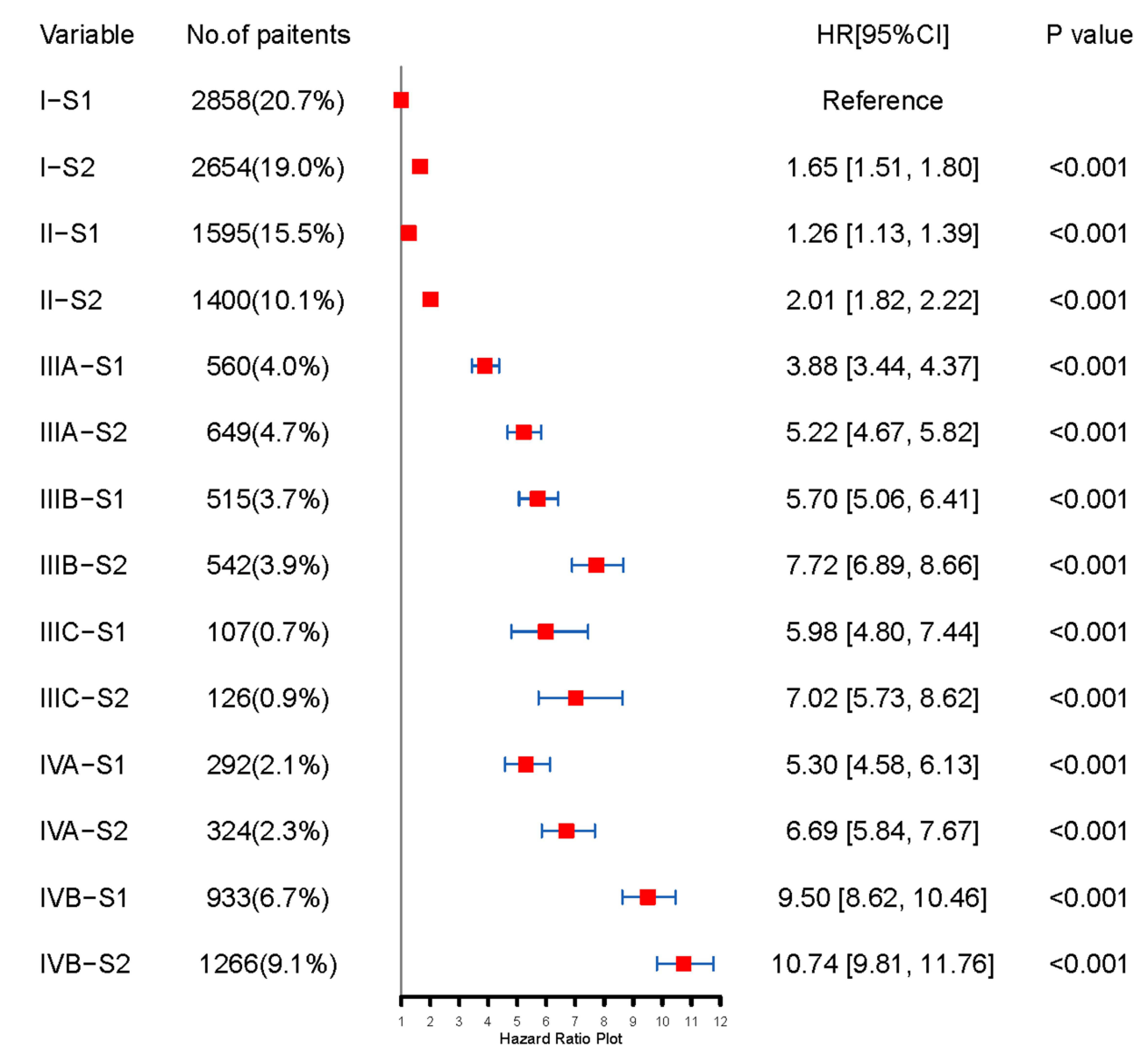

Figure 4 Prognostic value of TNM (tumor node metastasis)-SES (socioeconomic status) stage.

studies, our results also showed that patients of never married, divorced and widowed had higher risk of mortality (all $\mathrm{p}$ values $<0.001$ ). The favorable survival of married patients may be explained by the emotional support by spouse and the better financial situation, which may bring about better prognosis. It was reported ${ }^{17-19}$ that unmarried patients experienced more stress and depression and worse survival, compared to married patients. Elsewhere, one study ${ }^{20}$ found that depression and anxiety were significantly associated with breast cancer recurrence. In the meantime, married patients had better obedience to the prescribed surveillance and treatment than unmarried patients, which may result in higher rate of recurrence and worse prognosis. ${ }^{21-23}$

The insured status and higher household income reflected better financial status to cope with the increasing cost of health care. Several previous studies ${ }^{12,24,25}$ have demonstrated that patients with Medicaid and uninsured and lower household income have more advanced HCC tumor stage and unfavorable survival of patients with HCC. Patients with poor financial status experienced delays in access to regular HCC surveillance and were likely to receive surgery and transplantation, ${ }^{26-28}$ which may explain the worse prognosis of these patients.

As we expected, the education disparities have an impact on lifestyle, health care and disease surveillance and treatment. ${ }^{29-31}$ Higher education patients with $\mathrm{HCC}$ were younger than less educated patients due to more active health management. Several studies ${ }^{9,24}$ demonstrated that less education was significantly correlated with under-utilization of HCC surveillance and effective treatment, more advanced disease and unsatisfactory survival.

Recently, the association between socioeconomic status and population health had received more attention. Socioeconomic status is an important factor in health inequality, as a very robust positive association between socioeconomic status and health was confirmed. ${ }^{32}$ And socioeconomic status was correlated with not only cancer disease but also with chronic stress, heart disease, ulcers and type 2 diabetes. ${ }^{33}$ We constructed SES stage to divide the eligible 
patients into SES-1 stage (higher socioeconomic status) and SES-2 (lower socioeconomic status) stage by using HRs of four SES factors associated with CSS. In our analysis, higher SES patients were more likely to have an early stage of HCC and receive surgery, transplantation and chemotherapy. After adjusting for several confounders, such as age, race, sex and tumor stage, disparity of SES was significantly associated with CSS of patients with HCC. An explanation of this result is the combined influence of the four aforementioned factors.

Traditional AJCC TNM staging system was widely used to stratify patients for treatment selection and prognosis prediction in clinical practice. However, this algorithm focus only on the clinicopathological features of tumors and is not concerned with the socioeconomic status. As shown in our results, lower-SES stage revealed a 32.0\% increased risk of CSS, compared to higher-SES stage, indicating that SES was a significant prognostic predictor of survival. The C-index of TNM-SES stage was higher than that of TNM stage (0.735 vs 0.718$)$, indicating a superior predictive value. The vast majority of higher SES stage patients (expect IIIC) showed better prognosis in comparison with those who had lower SES stage in the same TNM stage. However, it was noted that there was no statistical difference in IIIC stage patients in terms of SES $(\mathrm{p}<0.384)$. This result may be explained by the following reason. First, relatively insufficient patients with IIIC stage may create statistical bias, which covers up the prognostic value of SES, compared with patients with other stages. Secondly, IIIC HCC stage is characterized by tumors with direct invasion of adjacent organs other than the gallbladder or with perforation of the visceral peritoneum. As represented in our study, the HR of IIIC stage was higher than that of IVA stage in same SES stage, indicating the dismal prognosis of patient with IIIC stage. The aggressive biological factors of IIIC stage may impair the effect of SES on survival. Interestingly, a higher HR was observed in patients with NBF1 stage compared with patients with NBF0 stage and more TNM stage, which revealed the superior prognostic value of SES stage. It was worth mentioning that there was no significant difference of HRs among the IIIB, III and IV at the corresponding SES stage, and even the higher HRs were observed in stage IIIB than at stage IVA in both SES stages. This result demonstrated that direct invasion of adjacent organs and lymph node metastasis may not have a valuable effect on prognosis of patients on HCC. It was reported in several studies ${ }^{34-36}$ that microvascular invasion was associated with unfavorable prognosis.

This large population-based information from the SEER database enhanced the generalizability and reliability of our investigation. However, it should be noted that there were several limitations in our study. First, the SES only incorporated five factors (insurance status, marital status, country percentage with bachelor's degree, country-level median household income and country percentage with employed) and attained four factors associated with CSS of patients with HCC in our study. Actually, SES also included other elements, such as religion, occupation and wealth, which were not registered in SEER database. Secondly, the TNM staging system registered in SEER database was not specific to HCC and commonly used in clinical practice. The burden of tumor, hepatic function and microvascular invasion also played a critical role in survival outcome of HCC, which was lacking in SEER database. Finally, there was no information about transcatheter arterial chemoembolization (TACE) and systemic therapy in SEER database, which was an important treatment for unresectable HCC. Despite these limitations, our large-scale comprehensive investigation revealed a significant effect of SES on staging, prognosis and clinical management for HCC.

\section{Conclusion}

Our comprehensive study revealed that SES was significantly associated with prognosis of patients with HCC after adjusting several confounders. The novel TNM-SES staging system, which combined TNM stage and SES stage, had more superior predictive value than the traditional TNM stage. Disparity on SES should receive more attention for patients with HCC in clinical management.

\section{Data Sharing Statement}

All data generated or analysed during this study are included in this published article.

\section{Ethics Approval and Consent to Participate}

We conducted this study in compliance with the institutional ethical standards and with the 1964 Helsinki declaration. The Ethics Committee and Institutional Review Board of Zhongshan Hospital of Fudan University approved our study. 
The SEER data-use agreement was attained to analyze the data from this data-set (ID:11452-Nov 2019). Since this study is based on a publicly available database without identifying patient information, written informed consent is not required.

\section{Author Contributions}

All authors made a significant contribution to the work reported, whether that is in the conception, study design, execution, acquisition of data, analysis and interpretation, or in all these areas; took part in drafting, revising or critically reviewing the article; gave final approval of the version to be published; have agreed on the journal to which the article has been submitted; and agree to be accountable for all aspects of the work.

\section{Funding}

No funding information was provided.

\section{Disclosure}

The authors declare that they have no conflicts of interest in this work.

\section{References}

1. Harding JJ, Abu-Zeinah G, Chou JF, et al. Frequency, morbidity, and mortality of bone metastases in advanced hepatocellular carcinoma. $J$ Natl Compreh Cancer Net. 2018;16(1):50-58. doi:10.6004/jnccn.2017.7024

2. Shaw JJ, Shah SA. Rising incidence and demographics of hepatocellular carcinoma in the USA: what does it mean? Expert Rev Gastroenterol Hepatol. 2011;5(3):365-370. doi:10.1586/egh.11.20

3.. European Association for the Study of the Liver. Electronic address eee, European Association for the Study of the L. EASL Clinical Practice Guidelines: management of hepatocellular carcinoma. J Hepatol. 2018;69(1):182-236. doi:10.1016/j.jhep.2018.03.019.

4. Rich NE, Murphy CC, Yopp AC, Tiro J, Marrero JA, Singal AG. Sex disparities in presentation and prognosis of 1110 patients with hepatocellular carcinoma. Aliment Pharmacol Ther. 2020;52(4):701-709. doi:10.1111/apt.15917

5. Zhang X, El-Serag HB, Thrift AP. Sex and race disparities in the incidence of hepatocellular carcinoma in the United States examined through age-period-cohort analysis. Cancer Epidemiol Biomarkers Prev. 2020;29(1):88-94. doi:10.1158/1055-9965.EPI-19-1052

6. Rungsakulkij N, Mingphruedhi S, Suragul W, Tangtawee P, Muangkaew P, Aeesoa S. Platelet-to-lymphocyte ratio and large tumor size predict microvascular invasion after resection for hepatocellular carcinoma. Asian Pac J Cancer Prev. 2018;19(12):3435-3441. doi:10.31557/ APJCP.2018.19.12.3435

7. Zhang J, Zhang Q, Lou Y, et al. Hypoxia-inducible factor-1 $\alpha /$ interleukin-1 $\beta$ signaling enhances hepatoma epithelial-mesenchymal transition through macrophages in a hypoxic-inflammatory microenvironment. Hepatology (Baltimore, Md). 2018;67(5):1872-1889. doi:10.1002/ hep. 29681

8. Sauzay C, Petit A, Bourgeois AM, et al. Alpha-foetoprotein (AFP): a multi-purpose marker in hepatocellular carcinoma. Clin Chim Acta. 2016;463:39-44. doi:10.1016/j.cca.2016.10.006

9. Shen Y, Guo H, Wu T, et al. Lower education and household income contribute to advanced disease, less treatment received and poorer prognosis in patients with hepatocellular carcinoma. J Cancer. 2017;8(15):3070-3077. doi:10.7150/jca.19922

10. Wong RJ, Kim D, Ahmed A, Singal AK. Patients with hepatocellular carcinoma from more rural and lower-income households have more advanced tumor stage at diagnosis and significantly higher mortality. Cancer. 2020;127(1):45-55. doi:10.1002/cncr.33211

11. Zhang W, Wang X, Huang R, et al. Prognostic value of marital status on stage at diagnosis in hepatocellular carcinoma. Sci Rep. 2017;7:41695. doi:10.1038/srep41695

12. Sobotka LA, Hinton A, Conteh LF. Insurance status impacts treatment for hepatocellular carcinoma. Ann Hepatol. 2019;18(3):461-465. doi:10.1016/j.aohep.2018.10.001

13. Aizer AA, Chen MH, McCarthy EP, et al. Marital status and survival in patients with cancer. J Clin Oncol. 2013;31(31):3869-3876. doi:10.1200/ JCO.2013.49.6489

14. Li Q, Gan L, Liang L, Li X, Cai S. The influence of marital status on stage at diagnosis and survival of patients with colorectal cancer. Oncotarget. 2015;6(9):7339-7347. doi:10.18632/oncotarget.3129

15. Wang L, Wilson SE, Stewart DB, Hollenbeak CS. Marital status and colon cancer outcomes in US Surveillance, Epidemiology and End Results registries: does marriage affect cancer survival by gender and stage? Cancer Epidemiol. 2011;35(5):417-422. doi:10.1016/j.canep.2011.02.004

16. Wang F, Xie X, Yang X, Jiang G, Gu J. The influence of marital status on the survival of patients with Hodgkin lymphoma. Oncotarget. 2017;8 (31):51016-51023. doi:10.18632/oncotarget.16879

17. Moreno-Smith M, Lutgendorf SK, Sood AK. Impact of stress on cancer metastasis. Future Oncol. 2010;6(12):1863-1881. doi:10.2217/fon.10.142

18. Molloy GJ, Stamatakis E, Randall G, Hamer M. Marital status, gender and cardiovascular mortality: behavioural, psychological distress and metabolic explanations. Soc Sci Med. 2009;69(2):223-228. doi:10.1016/j.socscimed.2009.05.010

19. Goldzweig G, Andritsch E, Hubert A, et al. Psychological distress among male patients and male spouses: what do oncologists need to know? Ann Oncol. 2010;21(4):877-883. doi:10.1093/annonc/mdp398

20. Burgess C, Cornelius V, Love S, Graham J, Richards M, Ramirez A. Depression and anxiety in women with early breast cancer: five year observational cohort study. BMJ. 2005;330(7493):702. doi:10.1136/bmj.38343.670868.D3 
21. Pajak TF, Laramore GE, Marcial VA, et al. Elapsed treatment days-a critical item for radiotherapy quality control review in head and neck trials: RTOG report. Int J Radiat Oncol Biol Phys. 1991;20(1):13-20. doi:10.1016/0360-3016(91)90132-n

22. Li BD, Brown WA, Ampil FL, Burton GV, Yu H, McDonald JC. Patient compliance is critical for equivalent clinical outcomes for breast cancer treated by breast-conservation therapy. Ann Surg. 2000;231(6):883-889. doi:10.1097/00000658-200006000-00013

23. Richardson JL, Shelton DR, Krailo M, Levine AM. The effect of compliance with treatment on survival among patients with hematologic malignancies. J Clin Oncol. 1990;8(2):356-364. doi:10.1200/JCO.1990.8.2.356

24. Hoehn RS, Hanseman DJ, Jernigan PL, et al. Disparities in care for patients with curable hepatocellular carcinoma. HPB (Oxford). 2015;17 (9):747-752. doi:10.1111/hpb.12427

25. Nguyen GC, Thuluvath PJ. Racial disparity in liver disease: biological, cultural, or socioeconomic factors. Hepatology. 2008;47(3):1058-1066. doi:10.1002/hep.22223

26. Singal AG, Mittal S, Yerokun OA, et al. Hepatocellular carcinoma screening associated with early tumor detection and improved survival among patients with cirrhosis in the US. Am J Med. 2017;130(9):1099-1106 e1. doi:10.1016/j.amjmed.2017.01.021

27. Kansagara D, Papak J, Pasha AS, et al. Screening for hepatocellular carcinoma in chronic liver disease: a systematic review. Ann Intern Med. 2014;161(4):261-269. doi:10.7326/M14-0558

28. Farvardin S, Patel J, Khambaty M, et al. Patient-reported barriers are associated with lower hepatocellular carcinoma surveillance rates in patients with cirrhosis. Hepatology. 2017;65(3):875-884. doi:10.1002/hep.28770

29. Clegg LX, Reichman ME, Miller BA, et al. Impact of socioeconomic status on cancer incidence and stage at diagnosis: selected findings from the surveillance, epidemiology, and end results: national Longitudinal Mortality Study. Cancer Causes Control. 2009;20(4):417-435. doi:10.1007/ s10552-008-9256-0

30. Brusselaers N, Ljung R, Mattsson F, et al. Education level and survival after oesophageal cancer surgery: a prospective population-based cohort study. BMJ Open. 2013;3(12):e003754. doi:10.1136/bmjopen-2013-003754

31. Byers TE, Wolf HJ, Bauer KR, et al. The impact of socioeconomic status on survival after cancer in the United States: findings from the National Program of Cancer Registries Patterns of Care Study. Cancer. 2008;113(3):582-591. doi:10.1002/cncr.23567

32. Adler NE, Boyce T, Chesney MA, et al. Socioeconomic status and health. The challenge of the gradient. Am Psychol. 1994;49(1):15-24. doi:10.1037//0003-066x.49.1.15

33. Salleh MR. Life event, stress and illness. Malays J Med Sci. 2008;15(4):9-18.

34. Sumie S, Nakashima O, Okuda K, et al. The significance of classifying microvascular invasion in patients with hepatocellular carcinoma. Ann Surg Oncol. 2014;21(3):1002-1009. doi:10.1245/s10434-013-3376-9

35. Bertuzzo VR, Cescon M, Ravaioli M, et al. Analysis of factors affecting recurrence of hepatocellular carcinoma after liver transplantation with a special focus on inflammation markers. Transplantation. 2011;91(11):1279-1285. doi:10.1097/TP.0b013e3182187cf0

36. Mazzaferro V, Llovet JM, Miceli R, et al. Predicting survival after liver transplantation in patients with hepatocellular carcinoma beyond the Milan criteria: a retrospective, exploratory analysis. Lancet Oncol. 2009;10(1):35-43. doi:10.1016/S1470-2045(08)70284-5

International Journal of General Medicine

Dovepress

\section{Publish your work in this journal}

The International Journal of General Medicine is an international, peer-reviewed open-access journal that focuses on general and internal medicine, pathogenesis, epidemiology, diagnosis, monitoring and treatment protocols. The journal is characterized by the rapid reporting of reviews, original research and clinical studies across all disease areas. The manuscript management system is completely online and includes a very quick and fair peer-review system, which is all easy to use. Visit http://www.dovepress.com/testimonials.php to read real quotes from published authors.

Submit your manuscript here: https://www.dovepress.com/international-journal-of-general-medicine-journal 